\title{
MATURIDADE EM GESTÃO DO CONHECIMENTO: ANÁLISE DAS PERCEPÇÕES DOS GESTORES DE UMA GRANDE EMPRESA DE CONSTRUÇÃO CIVIL
}

\section{MADUREZ DE LA GESTIÓN DEL CONOCIMIENTO: ANÁLISIS DE LAS PERCEPCIONES DE LOS GESTORES DE UNA GRAN EMPRESA DE CONSTRUCCIÓN CIVIL}

\author{
Carlos Henrique Cotta Natale* \\ Jorge Tadeu Ramos Neves** \\ Rodrigo Baroni de Carvalho***
}

\section{RESUMO}

Introdução: A partir da aplicação de um modelo de maturidade em Gestão do Conhecimento (GC), uma empresa pode ser capaz de identificar práticas de GC que podem ser melhoradas e, ou, implantadas.

Objetivo: O objetivo é identificar a percepção dos gestores em relação à maturidade das práticas de gestão do conhecimento em uma grande empresa de construção civil.

Metodologia: Trata-se de uma pesquisa descritiva qualitativa conduzida em duas etapas com o grupo dos 15 principais gestores (alta administração) por meio de uma entrevista e questionário semiestruturado (100 questões e 6 níveis) lastreado no modelo de maturidade Strategic Knowledge Management Maturity Model (KRUGER; SNYMAN, 2007b).

Resultados: Constatou-se que a empresa está no estágio inicial de GC. $\mathrm{O}$ modelo S-KMMM permitiu identificar iniciativas departamentais

*Mestre em Sistemas de Informação e Gestão do Conhecimento pela Universidade FUMEC (MG). Professor da Faculdade Cotemig. E-mail: carlos.natale@gmail.com

**Doutor em Génie Industriel et Gestion de L'innovation Technologique - École Centrale de Paris. Professor da Escola de Ciência da Informação da Universidade Federal de Minas Gerais (UFMG). E-mail: jtrneves@gmail.com

***Doutor em Ciência da Informação University of Toronto (Canadá). Professor do Programa de Pós-Graduação em Administração da PUCMinas. E-mail: baroni@pucminas.br

$$
\begin{gathered}
\text { Inf. Inf., Londrina, v. 21, n. 1, p. } 375 \text { - 406, jan./abr. } 2016 . \\
\text { http:www.uel.br/revistas/informacao/ }
\end{gathered}
$$


Carlos Henrique Cotta Natale; Jorge Tadeu Ramos Neves; Rodrigo Baroni de Carvalho

Maturidade em gestão do conhecimento: análise das percepções dos gestores de uma grande empresa de construção civil

isoladas e processos de GC que podem ser implantados e, ou, aprimorados.

Conclusões: Observou-se que a aplicação do modelo de maturidade em gestão do conhecimento foi útil para que os gestores da empresa reconhecessem que as práticas de GC correntes são realizadas de maneira isolada, intuitiva e informal. A aplicação do modelo S-KMMM se mostrou válida para avaliação sistemática e alinhamento estratégico das iniciativas organizacionais de GC.

Palavras-chave: Modelos de maturidade em gestão do conhecimento. Gestão do conhecimento. Mensuração do conhecimento. Construção civil.

\section{INTRODUÇÃO}

Para que a Gestão do Conhecimento (GC) possa ser compreendida com mais profundidade e aplicada pelas organizações, não basta apenas considerar conhecimento como um importante ativo no processo de tomada de decisão. Os modelos de maturidade em GC podem ajudar nessa tarefa, uma vez que, ao saber qual o seu estágio de maturidade em relação à $\mathrm{GC}$, as empresas podem identificar oportunidades de melhoria bem como trabalhar seus pontos fracos e, com isso, garantir que os processos de GC estarão sempre evoluindo (AUGUSTO, 2012; KURIAKOSE et al., 2010; PEE; KANKANHALLI, 2009; OLIVEIRA et al., 2011).

A avaliação do progresso dos processos relacionados à GC não é uma tarefa simples pois, além de o conhecimento ser um bem intangível e, por esse motivo, ser de difícil mensuração, também existem poucos estudos científicos focados em resultados da aplicação de modelos de maturidade em GC (OLIVEIRA et al., 2011, p. 12). Nesse sentido, os modelos de maturidade em GC vêm sendo pesquisados e criados para ajudar as organizações a entenderem quais passos são necessários para implantar ou melhorar a GC na empresa. Segundo Dalkir (2005, p. 206), a maior vantagem do uso de modelos de maturidade em gestão do 
Carlos Henrique Cotta Natale; Jorge Tadeu Ramos Neves; Rodrigo Baroni de Carvalho

Maturidade em gestão do conhecimento: análise das percepções dos gestores de uma grande empresa de construção civil

conhecimento é permitir que as organizações progridam de uma maneira ordenada, sem pular estágios importantes, permitindo assim alcançar os resultados desejados.

De acordo com Xavier (2010, p. 26), "um modelo de maturidade, ao se prestar a ser um ponto de partida na busca da melhoria, permite, então, identificar a situação atual da organização. Também permite a adoção de um vocabulário comum e de uma visão de futuro que pode e deve ser compartilhada". Ainda segundo Xavier (2010), os modelos de maturidade são utilizados por diversas áreas de atuação, sendo mais conhecidos os ligados a gestão de pessoas, gerência de projetos, engenharia de software e gestão da qualidade.

Nesta pesquisa, o foco são os modelos de maturidade em GC, cuja estrutura é semelhante à utilizada por modelos de outras áreas. Diversos são os modelos encontrados na literatura e muitas são as características compartilhadas entre eles. No entanto, a escolha do modelo mais adequado para ser aplicado em uma organização deve partir de uma análise mais profunda. É necessário conhecer as características do modelo, seus fatores e seus critérios metodológicos e, a partir disso, identificar o modelo de maturidade mais adequado para aplicação empírica (COSTA; MOURA; LUNA, 2009).

Um modelo de maturidade em GC pode ser usado, pela empresa, com a finalidade de identificar a evolução na aplicação das práticas e processos de GC e, também, de reconhecer as melhorias necessárias para que o resultado da GC esteja alinhado à gestão estratégica da empresa. Nesse contexto, o gestor tem um papel importante, pois, a partir de sua intervenção e de seu engajamento, a GC tende a ser incorporada mais intensamente à cultura organizacional da empresa e, com isso, seus resultados podem ser alavancados e o sucesso pode ser atingido mais facilmente (KRUGER; JOHNSON, 2010).

Desde o surgimento do conceito de GC no final dos anos 1990, tanto praticantes quanto pesquisadores da área têm envidado esforços 
Carlos Henrique Cotta Natale; Jorge Tadeu Ramos Neves; Rodrigo Baroni de Carvalho

Maturidade em gestão do conhecimento: análise das percepções dos gestores de uma grande empresa de construção civil

na compreensão conceitual do tema e também no desenvolvimento e aperfeiçoamento das boas práticas de implantação da GC. Por essa razão, desenvolver e aprimorar os modelos de maturidade em GC pode ser considerado um passo importante, tanto para a academia quanto para as organizações (SINHA, 2013).

Com esta pesquisa, pretende-se verificar as particularidades da aplicação de um modelo de maturidade em GC em uma empresa brasileira e, assim, descrever a análise dos resultados dessa aplicação. $\mathrm{Na}$ literatura, existem poucas evidências de trabalhos que têm como objetivo mensurar empiricamente a maturidade e, principalmente, atestar o crescimento na maturidade da GC nas organizações (KRUGER; JOHNSON, 2009). A partir de revisão sistemática na literatura sobre modelos de maturidade em GC, esta pesquisa visa contribuir por detalhar o processo de escolha e aplicação de um modelo de maturidade em GC em uma grande empresa brasileira do ramo da construção civil pesada. Os resultados obtidos com a aplicação do modelo podem ser usados para diversos fins: desde a orientação para o início de um projeto de implantação de GC, até a identificação dos processos que podem ser melhorados.

Neste contexto, este artigo pretende responder a seguinte pergunta: Qual a percepção dos gestores em relação à maturidade das práticas de gestão do conhecimento em uma empresa de construção civil pesada?

Além desta introdução, no item 2 deste artigo, é apresentado o referencial teórico sobre modelos de maturidade em GC. Já o item 3 apresenta a metodologia desta pesquisa e nos itens seguintes são apresentados os resultados e as conclusões deste artigo. 
Carlos Henrique Cotta Natale; Jorge Tadeu Ramos Neves; Rodrigo Baroni de Carvalho

Maturidade em gestão do conhecimento: análise das percepções dos gestores de uma grande empresa de construção civil

\section{REFERENCIAL TEÓRICO}

Os tópicos teóricos utilizados neste item apresentam as principais abordagens relacionadas à Gestão do Conhecimento e aos Modelos de Maturidade em Gestão do Conhecimento.

\subsection{Gestão do Conhecimento}

No contexto organizacional, conhecimento pode ser definido como uma crença justificada que aumenta a capacidade da empresa em efetivar ações (PEE; KANKANHALLI, 2009). O conhecimento, nesse contexto, é um ativo que deve ser gerenciado como outros ativos, porém, com uma atenção especial, pois se trata de um ativo intangível e de grande valor para as organizações (CHOI; LEE; YOO, 2010; DAVENPORT, 1998; KRUGER; JOHNSON, 2009; JUMO, 2011). A criação de conhecimento na empresa é fundamental. "As organizações devem usar a informação para criar significado, construir conhecimento e tomar decisões. A criação do conhecimento representa inovação e vantagem competitiva" (TARAPANOFF, 2006, p. 29).

Uma vez entendida a importância do conhecimento para as empresas, o desafio é gerenciá-lo sistematicamente e estrategicamente. Desde o advento da GC, várias foram as definições dadas por acadêmicos. Dalkir (2005) destaca que localizou mais de uma centena de diferentes definições para GC, sendo que, dessas, a autora considerou de boa qualidade a marca impressionante de 72 definições. Uma das conclusões do levantamento foi a caracterização da gestão do conhecimento como um campo multidisciplinar. A autora também propõe a seguinte definição:

Gestão do conhecimento é a coordenação sistemática e deliberada das tecnologias, processos, estruturas e pessoas que fazem parte da organização de forma a agregar valor através do reuso do conhecimento e da inovação. Essa coordenação é feita através da criação, compartilhamento e aplicação do conhecimento e 
Carlos Henrique Cotta Natale; Jorge Tadeu Ramos Neves; Rodrigo Baroni de Carvalho

Maturidade em gestão do conhecimento: análise das percepções dos gestores de uma grande empresa de construção civil

também através do enriquecimento da memória organizacional com lições aprendidas e melhores práticas, incentivando a aprendizagem contínua (DALKIR, 2005, p.3)

Algumas definições são voltadas a TI, outras focadas em aspectos mais culturais da GC. Algumas definições têm visão mais abrangente e holística da GC (SINHA, 2013) como, por exemplo, a definição dada por Baskerville e Dulipovici (2006). Os autores afirmam que, a GC surgiu como um importante campo para a prática e pesquisa em sistemas de informação. Este campo foi construído sobre bases teóricas da economia da informação, gestão estratégica, cultura organizacional, comportamento organizacional, estrutura organizacional, inteligência artificial, gestão da qualidade e medição de desempenho organizacional (BASKERVILLE; DULIPOVICI, 2006).

A ideia de interdisciplinaridade, apresentada por Baskerville e Dulipovici (2006), é confirmada por Kuriakose et al. (2010), que definem a GC como um campo interdisciplinar que abrange áreas como $\mathrm{Tl}$ e comunicação, sistemas de informação, gestão de mudanças, entre outros, no intuito de melhorar processos e o desempenho organizacional. Para Cuesta (2011), a GC representa uma ferramenta de gestão e as organizações devem utilizá-la para organizar e orientar eficientemente os sistemas de aprendizagem organizacional. Complementando esse conceito, Oliveira et al. (2011, p. 12) afirmam que a GC pode ser entendida "como um conjunto de processos que visam à criação, armazenamento, disseminação e utilização do conhecimento, alinhados com os objetivos de negócio, considerando fontes de conhecimento internas e externas à organização". Para Arazy e Gellatly (2012), a GC identifica e alavanca o conhecimento coletivo de uma organização para ajudá-la a competir.

De acordo com Ramanigopal (2012), a GC, que inicialmente era considerada um modismo, teve seu valor comprovado por diversas pesquisas. Ainda de acordo com Ramanigopal (2012), grandes 
Carlos Henrique Cotta Natale; Jorge Tadeu Ramos Neves; Rodrigo Baroni de Carvalho

Maturidade em gestão do conhecimento: análise das percepções dos gestores de uma grande empresa de construção civil

empresas contribuem e dedicam esforços para o desenvolvimento da GC, muitas vezes, como parte de sua estratégia de negócios, TI ou de gestão de recursos humanos. Além dos esforços internos, o autor afirma que existem empresas de consultoria que fornecem apoio no desenvolvimento da GC nas organizações e que esse apoio facilita 0 processo de implantação da GC.

Para que o conhecimento seja adequadamente gerenciado, as organizações devem tratá-lo como um recurso estratégico e considerar a gestão da tecnologia da informação como viabilizadora da GC. A GC refere-se a uma série de estratégias, práticas, técnicas, processos contínuos e sistemáticos, metodologias formais e informais, utilizados pelas organizações para identificar, criar, representar, processar, analisar, armazenar e distribuir o conhecimento, para o aprendizado de toda a organização, com a utilização adequada de tecnologias (KRUGER; JOHNSON, 2009). Essa foi a definição de GC escolhida como a mais aderente aos objetivos desse artigo.

\subsection{Modelos de maturidade em gestão do conhecimento}

De acordo com Van-de-Vem (1995), os modelos de maturidade em gestão têm como um dos seus objetivos explicar como ocorrem as mudanças nas organizações e, por esse motivo, muitos modelos foram criados a partir da teoria do ciclo de vida organizacional proposta por Smith, Mitchell e Summer (1985). Essa teoria considera que o desenvolvimento e as mudanças que ocorrem nas organizações seguem determinado padrão, que pode ser segmentado por estágios e, cada estágio, definido por fatores-chave, como, por exemplo, estratégia, pessoas, processos, tecnologias, entre outros.

Os métodos de implantação e mensuração da GC nas empresas estão diretamente ligados aos seus resultados, porque mensurar a GC pode ser uma ferramenta de controle e melhoria do desempenho organizacional e, também, pode permitir um alinhamento das ações da 
Carlos Henrique Cotta Natale; Jorge Tadeu Ramos Neves; Rodrigo Baroni de Carvalho

Maturidade em gestão do conhecimento: análise das percepções dos gestores de uma grande empresa de construção civil

GC às estratégias da organização. A GC pode ser avaliada a partir de duas dimensões que são: os indicadores de GC; e os níveis de maturidade em GC. Essas duas dimensões são complementares e, quando utilizadas em conjunto, podem aumentar a capacidade da empresa em gerenciar o seu conhecimento. Entretanto, existem muitas dificuldades para definição de métricas para o conhecimento, principalmente por se tratar de um bem intangível (GONÇALO; JUNGES; BORGES, 2010).

Para Pérez e Enrique (2012), um modelo de maturidade é um conjunto de práticas que são vinculadas a uma escala, com diversos passos descritos desde um nível inicial até um nível de excelência. Nesse sentido, os modelos de maturidade em GC são desenvolvidos para servirem de roteiro em uma avaliação da GC na empresa. Ao ser aplicado, o modelo apresenta um diagnóstico com o nível de maturidade em GC em que a empresa está naquele momento. Com isso, fatores que necessitam de mais desenvolvimento e atenção podem ser identificados e, consequentemente, melhorados. Além disso, os modelos de maturidade em GC estão ligados diretamente à implantação de GC nas empresas, e podem ser considerados mais uma ferramenta para isso, principalmente por fornecer ajuda para o melhor entendimento das estruturas, terminologias e processos de GC (KURIAKOSE et al., 2010).

Um modelo de maturidade em gestão de conhecimento define estágios de maturidade que uma organização pode alcançar para melhorar suas práticas de conhecimento centradas, em geral, em processos e em desempenho dos negócios. Assim, o modelo de maturidade descreve estágios identificáveis no caminho para alcançar a maturidade em gestão do conhecimento e ampliar as suas perspectivas, levando em consideração as atividades de gestão do conhecimento e as boas práticas nos processos de gestão do conhecimento (JUMO, 2011).

Um dos modelos de maturidade mais conhecidos é o Capability Maturity Model (CMM). Esse modelo foi criado na década de 1980 pelo 
Carlos Henrique Cotta Natale; Jorge Tadeu Ramos Neves; Rodrigo Baroni de Carvalho

Maturidade em gestão do conhecimento: análise das percepções dos gestores de uma grande empresa de construção civil

Instituto de Engenharia de Software Americano e tem como objetivo avaliar a maturidade dos processos de desenvolvimento de software. Nos últimos anos, esse modelo evoluiu para o CMMI (Capability Maturity Model Integration). Muitos modelos de maturidade em GC são baseados no $\mathrm{CMM}(\mathrm{I})$ e, por isso, coloca-se muita ênfase na tecnologia, negligenciando dimensões gerenciais e estratégicas desses modelos (KRUGER; SNYMAN, 2007b; SINHA, 2013).

De acordo com Sinha (2013), modelos de maturidade em GC podem ser utilizados para avaliar a capacidade de a empresa gerenciar seus ativos de conhecimento e, para isso, esses modelos devem fornecer um conjunto de padrões, práticas e processos de GC, com a finalidade de verificar a maturidade desses pontos. Um modelo pode fornecer, também, um roteiro de como implementar GC em uma organização.

Nesta pesquisa, o modelo de maturidade em GC, inicialmente proposto por Kruger e Snyman (2007a), e aperfeiçoado por Kruger e Johnson (2009) foi o selecionado para aplicação empírica. O modelo foi intitulado pelos autores como Strategic Knowledge Management Maturity Model e, nesta pesquisa, será chamado de S-KMMM. Para Kruger e Snyman (2007b), os modelos existentes na literatura privilegiam uma visão tecnológica da $\mathrm{GC}$ e deixam de lado a visão estratégica que, segundo os autores, é a perspectiva mais importante, pois, uma vez integrada à gestão estratégica da empresa, a GC pode trazer benefícios, como vantagem competitiva e maior inovação nos processos e produtos.

O S-KMMM é composto de seis fases e quatro estágios de maturidade. Além disso, o modelo contempla os fatores Pessoas, Processos, Tecnologias e Estratégia. Os estágios são denominados de Inicial, Consciente, Gerenciado e Otimizado. Cada fase contempla um determinado número de objetivos que precisam ser cumpridos e essa avaliação determina o estágio de maturidade em GC da empresa que o 
Carlos Henrique Cotta Natale; Jorge Tadeu Ramos Neves; Rodrigo Baroni de Carvalho

Maturidade em gestão do conhecimento: análise das percepções dos gestores de uma grande empresa de construção civil

aplicar. As fases são: Fase 1 - Tecnologia da Informação e Comunicação (TIC) e Gl como viabilizadores da gestão do conhecimento; Fase 2 - Decidir sobre princípios da gestão do conhecimento; Fase 3 - A capacidade de formular uma política de conhecimento para toda a organização; Fase 4 - Estratégia(s) de Construção de conhecimento; Fase 5 - Formulação de estratégias de gestão de conhecimento; Fase 6 - Conhecimento onipresente.

Com a integração das seis fases aos quatro estágios de maturidade, Kruger e Snyman (2007a) colocam as questões sobre a GC em uma ordem cronológica e, assim, propõem uma metodologia evolutiva no que diz respeito à progressão da GC em um ambiente organizacional. Os autores propõem uma metodologia construída sobre como determinar a progressão das questões estratégicas de negócios relacionados à gestão do conhecimento (KRUGER; SNYMAN, 2007a). Para que o S-KMMM possa ser aplicado na prática, Kruger e Snyman (2007b) propõem um questionário. O questionário é composto de cem (100) questões divididas nas seis fases. Todas as questões são de resposta obrigatória e o resultado indica o estágio de maturidade da empresa. O questionário proposto fornece uma ponte entre proposições teóricas e práticas, permitindo, não somente, que os profissionais de GC avaliem o nível de maturidade em gestão do conhecimento de uma organização, mas serve também como uma diretriz para institucionalizar os esforços de GC, tanto para a melhoria das práticas já aplicadas, quanto para as futuras (KRUGER; SNYMAN, 2007b).

Para formular o questionário, Kruger e Snyman (2007b) fizeram uma revisão da literatura e utilizaram outros modelos de maturidade em GC como guia. O questionário foi validado por estudiosos da área de GC, com o intuito de refinar as perguntas e de certificar-se de que as perguntas traçam um caminho lógico, para avaliar a maturidade em GC de empresas do setor público e do privado. Grande parte das perguntas valeu-se do uso de uma escala do tipo Likert, de quatro pontos, para 
Carlos Henrique Cotta Natale; Jorge Tadeu Ramos Neves; Rodrigo Baroni de Carvalho

Maturidade em gestão do conhecimento: análise das percepções dos gestores de uma grande empresa de construção civil

expressar o seu grau de acordo. Respostas do tipo "sim" ou "não" também são utilizadas. A escala dessa ferramenta de avaliação de maturidade em GC foi validada por um grupo de vinte pessoas. O grupo foi composto por acadêmicos e profissionais da área de GC. Para facilitar a captura de dados, o questionário final foi adaptado, para uso estatístico, em formatos eletrônicos (KRUGER; SNYMAN, 2007b; KRUGER; JOHNSON, 2009).

Usando o questionário proposto por Kruger e Snyman (2007b), uma pontuação global de maturidade GC pode ser calculada para a empresa. A pontuação total alcançada é calculada adicionando-se os resultados conseguidos em cada seção de maturidade. A pontuação das seções acompanha a seguinte distribuição: 20 pontos para a Fase 1; 76 pontos para a Fase 2; 88 pontos para a Fase 3; 94 pontos para a Fase 4; 76 pontos para a Fase 5; e 4 pontos para a Fase 6 ..

A maturidade em GC total é calculada somando-se os resultados alcançados nas seis seções individuais $(20+76+88+94+76+4)$, permitindo assim uma pontuação máxima de 358 pontos. Esse sistema de avaliação de maturidade foi projetado para calcular o total da maturidade em GC e o resultado pode ser expresso em valores absolutos, em percentagens, ou na indicação do estágio de maturidade. Cada respondente obteve uma pontuação, o que indica sua percepção em relação à maturidade da GC na empresa.

\section{METODOLOGIA}

De acordo com os critérios de classificação de pesquisa propostos por Vergara (2006), quanto aos fins, esta é uma pesquisa descritiva e aplicada. Quanto aos meios, é uma pesquisa de campo, bibliográfica e de estudo de caso. Já quanto à abordagem, esta pesquisa caracteriza-se como pesquisa qualitativa que, de acordo com Neves (1996, p. 1), "tem por objetivo traduzir e expressar o sentido dos 
Carlos Henrique Cotta Natale; Jorge Tadeu Ramos Neves; Rodrigo Baroni de Carvalho

Maturidade em gestão do conhecimento: análise das percepções dos gestores de uma grande empresa de construção civil

fenômenos do mundo social; trata-se de reduzir a distância entre indicador e indicado, entre teoria e dados, entre contexto e ação." No entanto, mesmo sendo qualitativa, parte dos dados coletados é apresentada por meio de estatística descritiva, para facilitar a compreensão do estudo de caso. De acordo com Manly (2008), a estatística descritiva pode ser utilizada na identificação de padrões em uma amostra determinada.

Os dados foram coletados por meio de entrevistas semiestruturadas e pela aplicação de um questionário. A empresa selecionada para o estudo de caso é do segmento da construção civil pesada e foi escolhida pelo critério de conveniência e acessibilidade. A construtora em questão tem mais de 30 anos e está entre as 20 maiores do Brasil, com obras na América Latina e África para clientes tanto da iniciativa privada quanto da área pública. A construtora é especializada na construção de rodovias, portos, barragens, gasodutos, túneis bem como implantação de áreas industriais e projetos de saneamento e mineração de larga escala. Até o final de 2013, a empresa contava com cerca de 4000 funcionários e é certificada nas normas ISO 9.001 (International Organization for Standartization) de gestão da qualidade, ISO 14.001 de gestão ambiental e OSHAS 18.001 de saúde e segurança ocupacional pelo BVQI (Bureau Veritas Quality International). Tem também o certificado Programa Brasileiro de Qualidade e Produtividade do Habitat (PBQP-H). Neste artigo, a empresa é identificada como Empresa "A".

Os respondentes das entrevistas e dos questionários foram definidos por tipicidade, uma vez que um dos autores deste artigo possui conhecimento sobre o universo pesquisado. Foram 15 os gestores participantes da pesquisa. Eles estão identificados de E1 à E15. Sendo E1-Superintendente Administrativo; E2-Superintendente Contadoria; E3Superintendente Logística e Compras; E4-Superintendente Obras; E5Gerente Comércio Exterior; E6-Gerente Departamento Pessoal; E7- 
Carlos Henrique Cotta Natale; Jorge Tadeu Ramos Neves; Rodrigo Baroni de Carvalho

Maturidade em gestão do conhecimento: análise das percepções dos gestores de uma grande empresa de construção civil

Gerente Financeiro Internacional; E8-Gerente Financeiro Nacional; E9Gerente Logística; E10-Gerente Orçamento; E11-Gerente Planejamento e Controle; E12-Gerente Qualidade e Segurança do Trabalho; E13Gerente Recursos Humanos; E14-Coordenador Tecnologia da Informação; E15-Coordenador Telecomunicações.

As entrevistas foram gravadas e, posteriormente, transcritas, tendo seguido dois roteiros: primeiro, uma entrevista semiestruturada foi realizada e direcionada ao principal executivo da empresa, com o objetivo de colher informações sobre a organização, além de medir a percepção do gestor em relação às práticas de GC na empresa; o segundo modelo de entrevista teve como público-alvo o principal gestor de cada setor da empresa. O objetivo da entrevista foi alinhar conceitos importantes, colher informações profissionais sobre os entrevistados e explicar detalhes sobre o questionário que foi enviado aos gestores. Finalizadas as entrevistas, a próxima etapa da pesquisa foi o envio do questionário proposto como ferramenta de avaliação da maturidade em GC. Antes da aplicação dos questionários, um pré-teste foi realizado com três funcionários da empresa objeto do estudo de caso. $\mathrm{O}$ objetivo do pré-teste foi verificar o tempo necessário para respondê-lo, verificar se o vocabulário utilizado estava adequado e se todas as perguntas estavam claras.

O questionário foi utilizado como ferramenta de aplicação e avaliação do modelo e levou em consideração a metodologia do modelo escolhido. O questionário, originalmente disponível em língua inglesa, foi traduzido por meio da técnica da tradução reversa com o objetivo de eliminar as possíveis inconsistências linguísticas.

Em seguida, foi empregada a técnica de análise de conteúdo para as entrevistas. Segundo Campos (2004, p. 613), "a análise de conteúdo, como conjunto de técnicas, se vale da comunicação como ponto de partida. Diferente de outras técnicas [...], é sempre feita a partir da mensagem e tem por finalidade a produção de inferências." 
Carlos Henrique Cotta Natale; Jorge Tadeu Ramos Neves; Rodrigo Baroni de Carvalho

Maturidade em gestão do conhecimento: análise das percepções dos gestores de uma grande empresa de construção civil

Já para a análise dos resultados do questionário, foi utilizada a metodologia proposta pelo modelo aplicado, em conjunto com a técnica de análise de estatística descritiva. Para a tabulação dos dados colhidos por meio dos questionários e para realização dos cálculos utilizados na descrição estatística dos resultados, bem como para a criação dos gráficos da pesquisa, optou-se pelo uso do Microsoft Excel 2013.

\section{RESULTADOS E DISCUSSÃo}

A coleta dos dados da pesquisa foi realizada entre 28 de outubro de 2013 e 23 de dezembro de 2013. Os gestores selecionados estão distribuídos em diversas áreas da empresa estudada. Todos foram previamente entrevistados e convidados a responder ao questionário utilizado como ferramenta de avaliação de maturidade da GC na organização.

Dos 15 gestores participantes, quatro são considerados gestores sêniores (Superintendentes), nove são considerados gestores plenos (Gerentes) e, dois são considerados gestores júniores (Coordenadores). Já em relação à formação acadêmica dos gestores, um possui graduação, dois possuem Mestrado, e 12 possuem MBA (Master in Business Administration) e, ou, Especialização.

Em relação ao tempo de empresa, o gestor com mais tempo está há 23 anos como funcionário e o gestor com menos tempo está há três anos na Empresa "A". Em relação aos cargos que ocupam atualmente na empresa, o gestor com mais tempo está há 15 anos no cargo e o gestor com menos tempo está há um ano no cargo. Na média, os 15 participantes da pesquisa estão há 10,3 anos na empresa e há 4,5 anos nos cargos atuais.

A entrevista inicial com os quinze gestores serviu para alinhar conceitos e para familiarizar os gestores com a pesquisa. Em seguida, os gestores foram convidados a responder a um questionário. Esse 
Carlos Henrique Cotta Natale; Jorge Tadeu Ramos Neves; Rodrigo Baroni de Carvalho

Maturidade em gestão do conhecimento: análise das percepções dos gestores de uma grande empresa de construção civil

questionário teve como objetivo verificar a percepção de cada gestor em relação à GC na Empresa "A". Durante as entrevistas, foi possível identificar como cada gestor percebe e entende a GC. Todos foram incentivados a definir genericamente a GC.

Os gestores E2, E4, E5, E6, E7, E8, tinham pouca ou nenhuma consciência sobre o termo gestão do conhecimento ou não sabiam conceituá-lo. Sendo assim, o entrevistador deu uma explicação prévia para alinhar os conceitos e prosseguir com a entrevista. Os gestores E13 e E15 afirmaram compreender o conceito de GC, mas explicaram com exemplos, não sendo possível extrair um conceito propriamente dito de suas palavras. Todavia, pela clareza dos exemplos dados por esses gestores, percebe-se um bom entendimento do termo GC.

Em geral, todos os gestores que conseguiram fazer uma definição do termo GC aproximaram-se da definição eleita nesta pesquisa (KRUGER; JOHNSON, 2009) e demostraram algum conhecimento sobre o assunto. No entanto, alguns gestores têm uma visão mais limitada sobre o tema, como, por exemplo, E12, que tem uma visão da GC muito voltada a normas e processos. O mesmo ocorre com o gestor E13, que demonstrou ter clareza sobre o tema, mas acredita que a GC é uma atividade relacionada à área de recursos humanos, exclusivamente. Já os gestores E2, E4, E5, E6, E7, E8, após escutarem a explicação sobre o que é GC, tiveram clareza sobre o tema e conseguiram perceber algumas iniciativas em seus respectivos setores e na empresa como um todo.

Conforme Pee e Kankanhalli (2009) e Fontanillas, Cruz e Gonçalves (2012), os fatores Pessoas, Processos e Tecnologias podem ser considerados atributos importantes para a GC. O entrevistador explicou esses fatores e, em seguida, perguntou aos gestores, na percepção de cada um, qual é o fator mais importante para a GC e qual pode ser considerado o fator mais maduro na organização. 
Carlos Henrique Cotta Natale; Jorge Tadeu Ramos Neves; Rodrigo Baroni de Carvalho

Maturidade em gestão do conhecimento: análise das percepções dos gestores de uma grande empresa de construção civil

Nenhum dos 15 gestores entrevistados considera o fator Tecnologia, isoladamente, como o fator mais importante. Mesmo os gestores E5, E6, E7 e E12, que afirmaram que os três fatores têm a mesma importância nas práticas de GC, ainda assim consideraram, como os demais gestores, a Tecnologia apenas como um meio para se fazer GC. Observou-se que a maioria dos gestores (8 de 15) considera o fator Pessoas o mais importante. Esse resultado corrobora o que é afirmado por Pee e Kankanhalli (2009) e por Fontanillas, Cruz e Gonçalves (2012), que consideram o fator Pessoas o mais importante para o desenvolvimento das práticas de GC em uma empresa.

Em contrapartida, cinco gestores consideram a tecnologia o fator mais maduro na Empresa "A", e os gestores E6, E7 e E12 apontaram que os três fatores são igualmente maduros, mesmo considerando que o fator Tecnologia pareça um pouco à frente dos demais. As respostas dos gestores corroboram a percepção de Kruger e Snyman (2007a), Pee e Kankanhalli (2009) e de Fontanillas, Cruz e Gonçalves (2012), que afirmam que as empresas usualmente privilegiam o fator Tecnologia nos processos de GC.

Esta primeira etapa das entrevistas serviu para alinhar os conceitos sobre a GC e seus fatores-chave e para uma explicação geral sobre maturidade em GC e o questionário que foi aplicado. De acordo com as respostas dos gestores, foi possível constatar nesta primeira etapa que, que não há um consenso nem sobre a GC, nem sobre os seus fatores-chave (Pessoas, Processos e Tecnologias). Isso pode indicar que cada setor trabalha isoladamente a GC ou, então, que não há uma política formal de GC na empresa.

Após a entrevista, os gestores foram convidados a responder ao questionário utilizado como ferramenta de avaliação da maturidade em GC. O questionário, com 100 afirmações (V1-V100), foi respondido pelos 15 gestores entrevistados e, a partir do resultado, a maturidade em GC, da Empresa "A", foi medida. 
Carlos Henrique Cotta Natale; Jorge Tadeu Ramos Neves; Rodrigo Baroni de Carvalho

Maturidade em gestão do conhecimento: análise das percepções dos gestores de uma grande empresa de construção civil

Como definido por Para a Fase 1 do S-KMMM (KRUGER; SNYMAN, 2007a), a empresa não demonstrou ter ciência do papel do conhecimento como recurso estratégico. As TIC se estiverem presentes dentro da organização, não são gerenciadas de forma eficaz e eficiente. A organização lida com os dados e as informações de maneira desorganizada e os sistemas e tecnologias existentes ainda não estão maduros. Nessa fase, grande parte do conhecimento organizacional é tácito. Se esse conhecimento está sendo compartilhado, isso ocorre de maneira informal e casual. São cinco as questões dessa fase (V1-V5), divididas em duas seções. De acordo com a metodologia de avaliação do modelo S-KMMM, a maturidade da Fase 1 na Empresa "A" é de 69\%. Pode-se observar, pelo Gráfico 1, que dois dos 15 gestores consideram essa fase $100 \%$ atendida, sendo essa a pontuação máxima alcançada.

Gráfico 1 - Maturidade da Fase 1

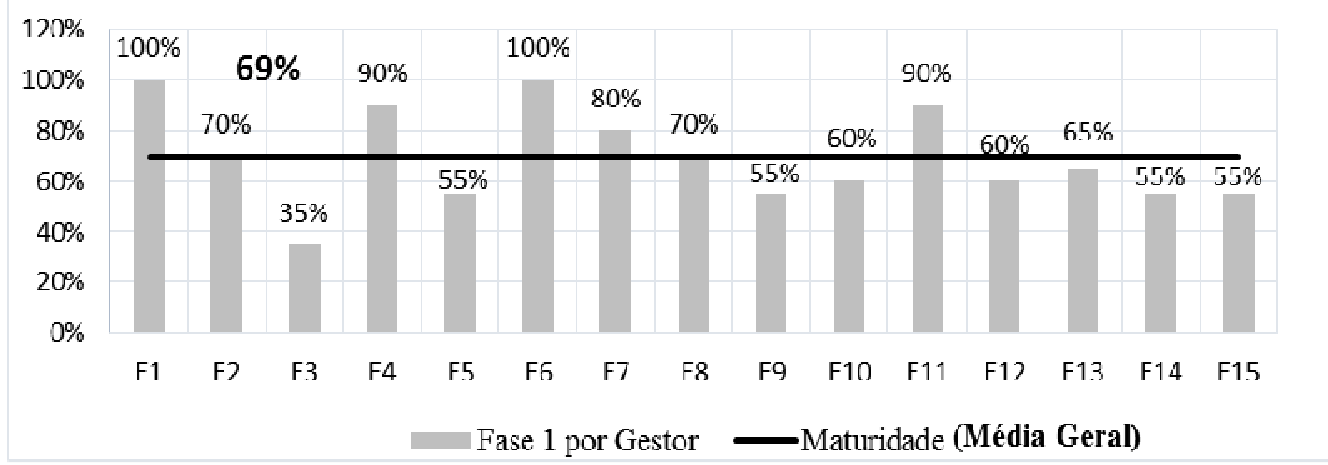

Fonte: Dados da pesquisa.

A pontuação mínima foi de $35 \%$, resultado obtido pelas respostas do gestor E3. Esse mesmo gestor (E3), durante a fase de entrevistas, considerou a Tecnologia como o fator mais maduro da Empresa "A". $\mathrm{Na}$ Fase $1,83 \%$ das respostas foram positivas e $17 \%$ negativas. Porém, $50 \%$ das respostas foram "Sim, mas não significativamente" que, mesmo sendo uma resposta positiva, indica que existe muito a ser melhorado no que diz respeito à TIC como suporte à GC. 
Carlos Henrique Cotta Natale; Jorge Tadeu Ramos Neves; Rodrigo Baroni de Carvalho

Maturidade em gestão do conhecimento: análise das percepções dos gestores de uma grande empresa de construção civil

Kruger e Snyman (2007a) definiram que, na fase 2 do S-KMMM, os sistemas e tecnologias da empresa evoluem e a empresa já sabe como trabalhar os dados e as informações disponíveis. Há uma percepção da importância do conhecimento, bem como um reconhecimento da GC como fator estratégico. Os esforços da GC começam com a identificação de problemas, fatores para o sucesso e elementos para que a cultura do conhecimento seja incorporada na empresa. Mesmo tendo essa percepção inicial da importância da GC na empresa, não há uma visão de futuro para o conhecimento atrelado à gestão estratégica. As dezenove questões dessa fase (V6-V24) estão divididas em quatro seções.

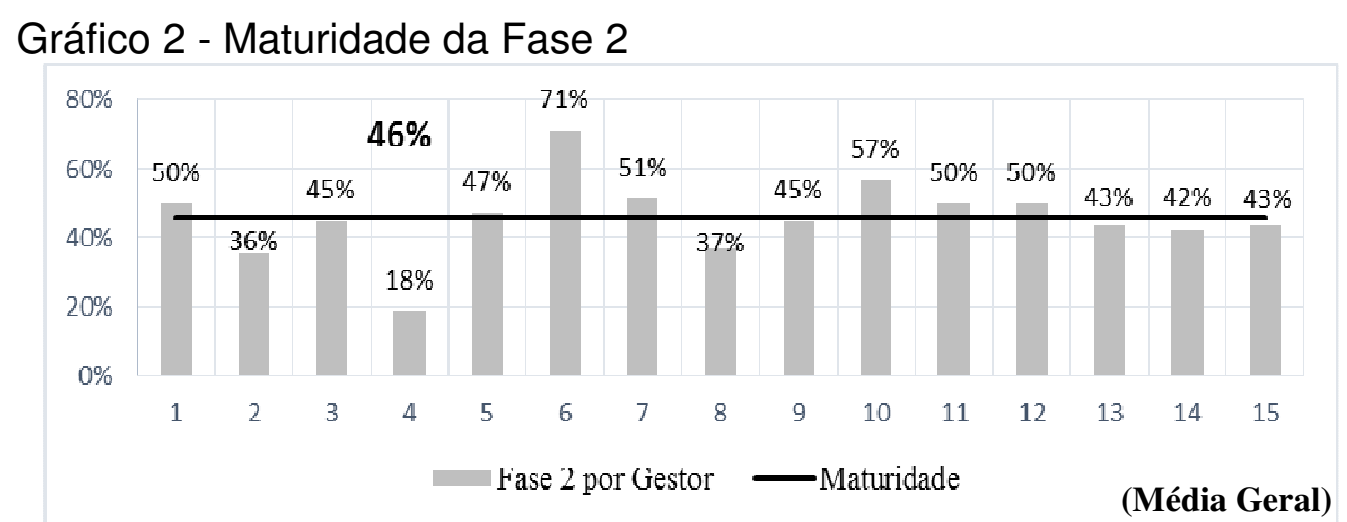

Fonte: Dados da pesquisa.

Seguindo os critérios metodológicos propostos para a avaliação do modelo S-KMMM, a maturidade da Fase 2 na Empresa "A" é de $46 \%$. Pode-se observar, no Gráfico 2, que nenhum gestor considera essa fase $100 \%$ atendida, sendo $71 \%$ a pontuação máxima alcançada (E6). A pontuação mínima foi de $18 \%$, resultado obtido pelas respostas do gestor E4. Assim como na Fase 1, nessa fase a maioria das respostas foi positiva (63\%) e $37 \%$ foram respostas negativas. Entretanto, apenas $9 \%$ das respostas foram um "Sim, definitivamente". Esse resultado indica uma necessidade grande de aperfeiçoamento e melhoria nos processos, para que o nível de maturidade da Fase 2 atinja o completo 
Carlos Henrique Cotta Natale; Jorge Tadeu Ramos Neves; Rodrigo Baroni de Carvalho

Maturidade em gestão do conhecimento: análise das percepções dos gestores de uma grande empresa de construção civil

atendimento, pois para que o resultado da fase seja completo, $100 \%$ das respostas devem ser um "Sim, definitivamente".

Já na Fase 3 do modelo S-KMMM, a empresa já é capaz de formular uma política de conhecimento que englobe toda a organização. Nessa política, os principais pontos são gerenciar e proteger 0 conhecimento como um recurso estratégico. Também na Fase 3, repositórios de conhecimento são definidos. Nesse nível de maturidade, sistemas TIC evoluem para um patamar em que são capazes de ir além do apoio às operações da empresa, passando a ser capazes de suportar as decisões dentro da estratégia de GC. Ao final da Fase 3, a empresa já entende a importância do conhecimento e de sua gestão, e procura introduzir a cultura do compartilhamento do conhecimento como forma de impulsionar os resultados da GC. São 24 as questões dessa fase (V25-V48), divididas em cinco seções.

\section{Gráfico 3 - Maturidade da Fase 3}

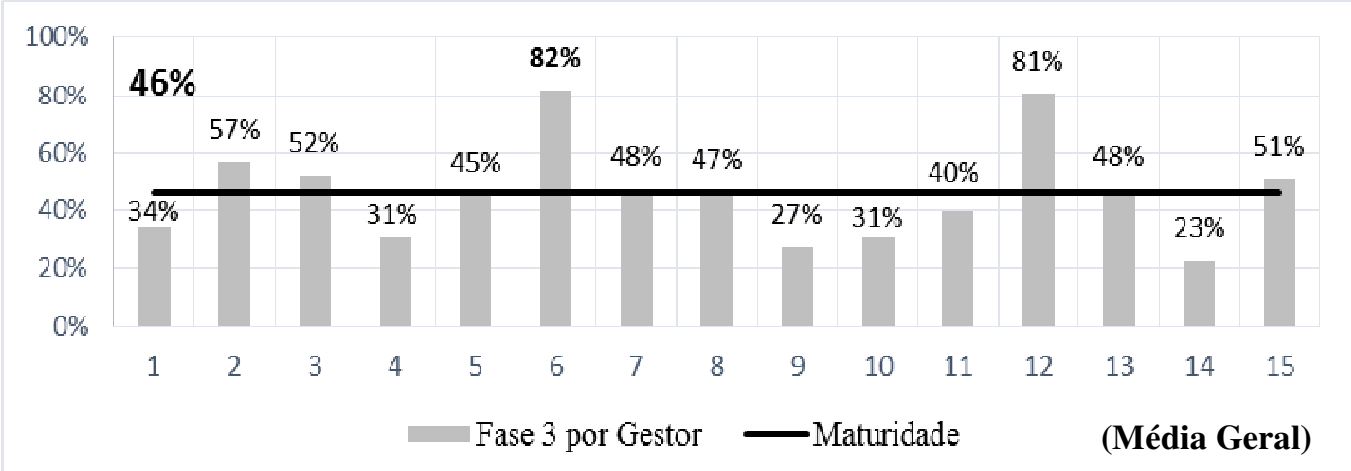

Fonte: Dados da pesquisa.

Considerando o resultado do questionário, a maturidade da Fase 3 na Empresa "A" é de 46\%. Pode-se observar, pelo Gráfico 3, que nenhum gestor considera essa fase $100 \%$ atendida, sendo $82 \%$ a pontuação máxima alcançada (E6). A pontuação mínima foi de $23 \%$, resultado obtido pelas respostas do gestor E14. Percebe-se, pelos resultados, que os gestores E6 e E12 têm uma percepção extremamente otimista e o reflexo foi o resultado alto na Fase 3 (82\% e 
Carlos Henrique Cotta Natale; Jorge Tadeu Ramos Neves; Rodrigo Baroni de Carvalho

Maturidade em gestão do conhecimento: análise das percepções dos gestores de uma grande empresa de construção civil

$81 \%$, respectivamente). De maneira geral, $59 \%$ das respostas nessa fase foram positivas (total ou parcialmente) e $41 \%$ foram respostas negativas. Contudo, para atingir a plenitude da fase, $100 \%$ das respostas precisam ser positivas (Sim, definitivamente) e, na Fase 3, apenas $27 \%$ o foram. Isso pode indicar que muitos processos e práticas precisam ser implantados e a cultura da GC precisa ser institucionalizada.

$\mathrm{Na}$ fase 4 do S-KMMM, a arquitetura de TIC da empresa é considerada eficiente e eficaz. A infraestrutura de conhecimento está construída e funciona. Os gestores, conscientemente, começam a incentivar seus funcionários a praticar a GC. A organização, nesse nível de maturidade, é capaz de determinar o que constitui seus recursos de conhecimento (tanto tácito e explícito), onde estão os recursos de conhecimento (fontes internas e externas), e porque os recursos são estratégicos. Nessa fase, a formulação de estratégias de negócios com base em GC começa a ter resultados. São 32 as questões (afirmações) dessa fase (V49-V80), divididas em sete seções.

\section{Gráfico 4 - Maturidade da Fase 4}

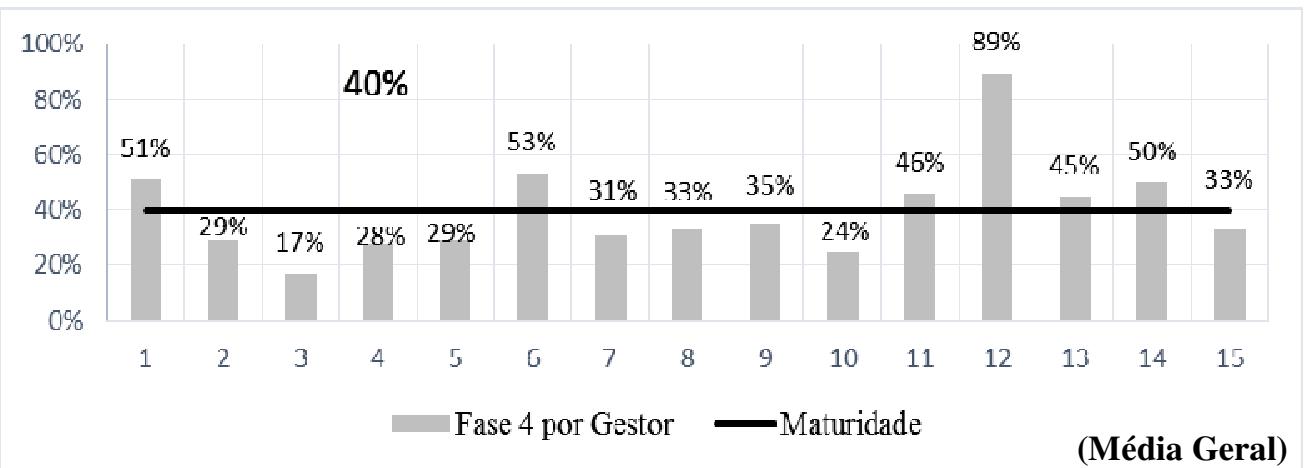

Fonte: Dados da pesquisa.

A maturidade da Empresa "A" percebida na Fase 4 é de 40\%. Pode-se observar, pelo Gráfico 4, que nenhum gestor considera essa fase $100 \%$ atendida, sendo $89 \%$ a pontuação máxima alcançada (E12). A pontuação mínima foi de $17 \%$, resultado obtido pelas respostas do 
Carlos Henrique Cotta Natale; Jorge Tadeu Ramos Neves; Rodrigo Baroni de Carvalho

Maturidade em gestão do conhecimento: análise das percepções dos gestores de uma grande empresa de construção civil

gestor E3. Percebe-se, pelos resultados, que o gestor E12 tem uma percepção extremamente otimista, cujo reflexo foi o resultado alto na Fase 4 (89\%). As respostas do gestor E12 destoaram das dos demais gestores.

Esse comportamento pode indicar que o gestor não compreendeu as perguntas ou que, em seu setor, a GC está mais evoluída. Entretanto, durante a entrevista, não fica evidente essa evolução no uso de práticas e processos de GC pelo setor gerido por E12. Outro ponto a ser observado é em relação ao padrão de respostas. Na Fase 4, 45\% foram respostas positivas (total ou parcialmente) e $55 \%$ foram negativas.

Kruger e Snyman (2007a) afirmam que, na Fase 5 do S-KMMM, os responsáveis pela gestão estratégica da empresa começam a perceber as TIC e a GC como entidades interdependentes e insubstituíveis. Percebem também que ambas são de suma importância no intuito de sustentar a vantagem competitiva. A organização compreende a necessidade de reter conhecimento e enxerga a importância do seu capital intelectual. Nessa fase, o conhecimento dos recursos humanos internos é mais bem aproveitado. A organização é capaz de formular planos eficientes e eficazes para gerenciar a sua estrutura de conhecimento e das TIC.

A organização, na Fase 5, tem como objetivo institucionalizar o conhecimento e os sistemas de TIC, que, por sua vez, vão gradualmente aumentando sua eficácia e eficiência, tornando a capacidade da organização em explorar, criar, adquirir, transferir, capturar, codificar, compartilhar e distribuir conhecimento cada vez mais madura. São 19 as questões (afirmações) dessa fase (V81-V99), divididas em duas seções.

Na Empresa "A", a maturidade da Fase 5, é de 46\%. Pode-se observar, pelo Gráfico 5, que nenhum gestor considera essa fase $100 \%$ atendida, sendo $61 \%$ a pontuação máxima alcançada (E13). A pontuação mínima foi de $16 \%$, resultado obtido pelas respostas do 
Carlos Henrique Cotta Natale; Jorge Tadeu Ramos Neves; Rodrigo Baroni de Carvalho

Maturidade em gestão do conhecimento: análise das percepções dos gestores de uma grande empresa de construção civil

gestor E6. Observa-se, no padrão de respostas da Fase 5, que 61\% das respostas foram positivas, sendo $27 \%$ "Sim, definitivamente" e $34 \%$ "Sim, mas não significativamente"; e 39\% negativas, sendo 9\% "Não, mas ocorrerá dentro dos próximos 5 anos" e 30\% "Não".

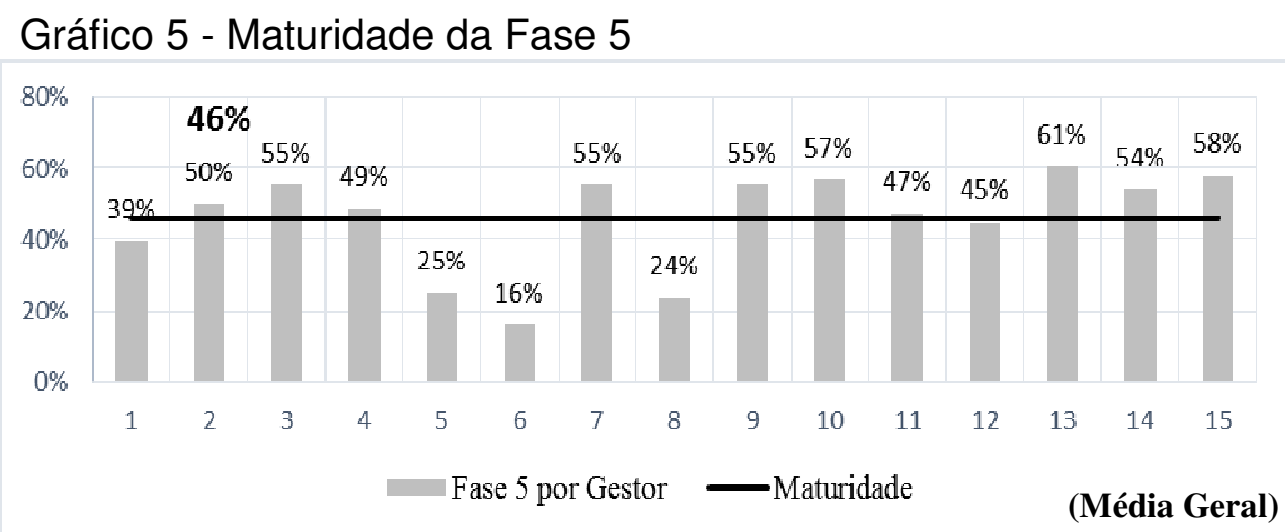

Fonte: Dados da pesquisa.

Como definido por Kruger e Snyman (2007a), na Fase 6 do S$\mathrm{KMMM}$, a GC está perfeitamente integrada à estratégia da empresa e também a todo o seu ecossistema (clientes, parceiros de negócios, acionistas, fornecedores). A arquitetura de TIC da organização deve ser capaz de transcender as fronteiras da organização. O foco não é apenas determinar se o conhecimento está sendo ou não compartilhado entre parceiros da cadeia de valor, mas se a GC está institucionalizada entre a empresa e seus parceiros. Isso significa que a organização retorna à Fase 1 do modelo de maturidade e, mais uma vez, o progresso por meio de todas essas fases é necessário. Nessa nova rodada, adicionam-se questões como: conhecimentos aplicáveis a todas as partes interessadas, formulação de uma política de conhecimento para governança do conhecimento, elaboração de estratégias de conhecimento holístico, etc. Nessa fase, uma única pergunta faz parte da ferramenta de avaliação (V100). 
Carlos Henrique Cotta Natale; Jorge Tadeu Ramos Neves; Rodrigo Baroni de Carvalho

Maturidade em gestão do conhecimento: análise das percepções dos gestores de uma grande empresa de construção civil

Gráfico 6 - Maturidade da Fase 6

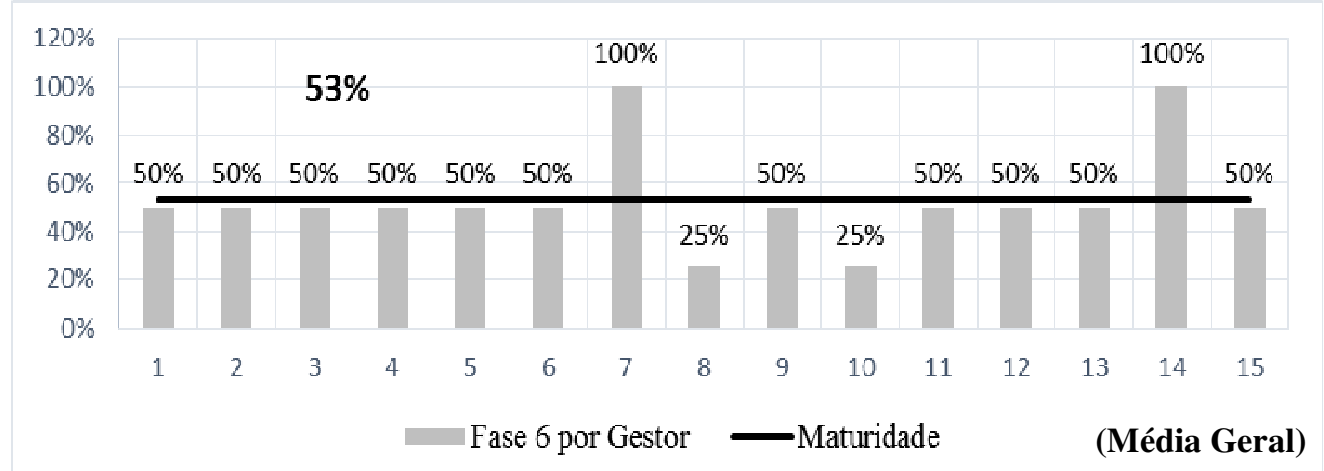

Fonte: Dados da pesquisa.

De acordo com a metodologia de avaliação do modelo S-KMMM, a maturidade da Fase 6, na Empresa "A", é de 53\%. Pode-se observar, pelo Gráfico 6, que dois gestores consideram essa fase $100 \%$ atendida, sendo essa a pontuação máxima alcançada (E17 e E14). A pontuação mínima foi de $25 \%$, resultado obtido pelas respostas dos gestores E8 e E10. Dos 15 gestores, dois consideram que, nos últimos cinco anos, a Empresa " $A$ " experimentou um rápido crescimento em sua maturidade em GC; outros 11 gestores consideraram que houve algum crescimento, mesmo que não significativo; e dois gestores consideraram que não houve crescimento, mas acreditam que haverá dentro dos próximos cinco anos.

Por fim, a maturidade geral da GC, de acordo com o modelo SKMMM, é medida por meio da média aritmética simples da pontuação obtida por todos os respondentes da ferramenta de avaliação. O resultado pode ser descrito pela porcentagem obtida, por valor absoluto ou pelo nível de maturidade. A partir das respostas dos 15 gestores à ferramenta de avaliação da GC na Empresa "A", observa-se que o nível de maturidade em GC, na organização pesquisada, é de 46\% (GRÁFICO 7). A pontuação média foi de 163,6 pontos, dos 358 possíveis. Em relação ao nível de maturidade, a Empresa "A" está no nível 1, chamado por Kruger e Snyman (2007a) de "Inicial". 
Carlos Henrique Cotta Natale; Jorge Tadeu Ramos Neves; Rodrigo Baroni de Carvalho

Maturidade em gestão do conhecimento: análise das percepções dos gestores de uma grande empresa de construção civil

Gráfico 7 - Maturidade em GC da Empresa "A"

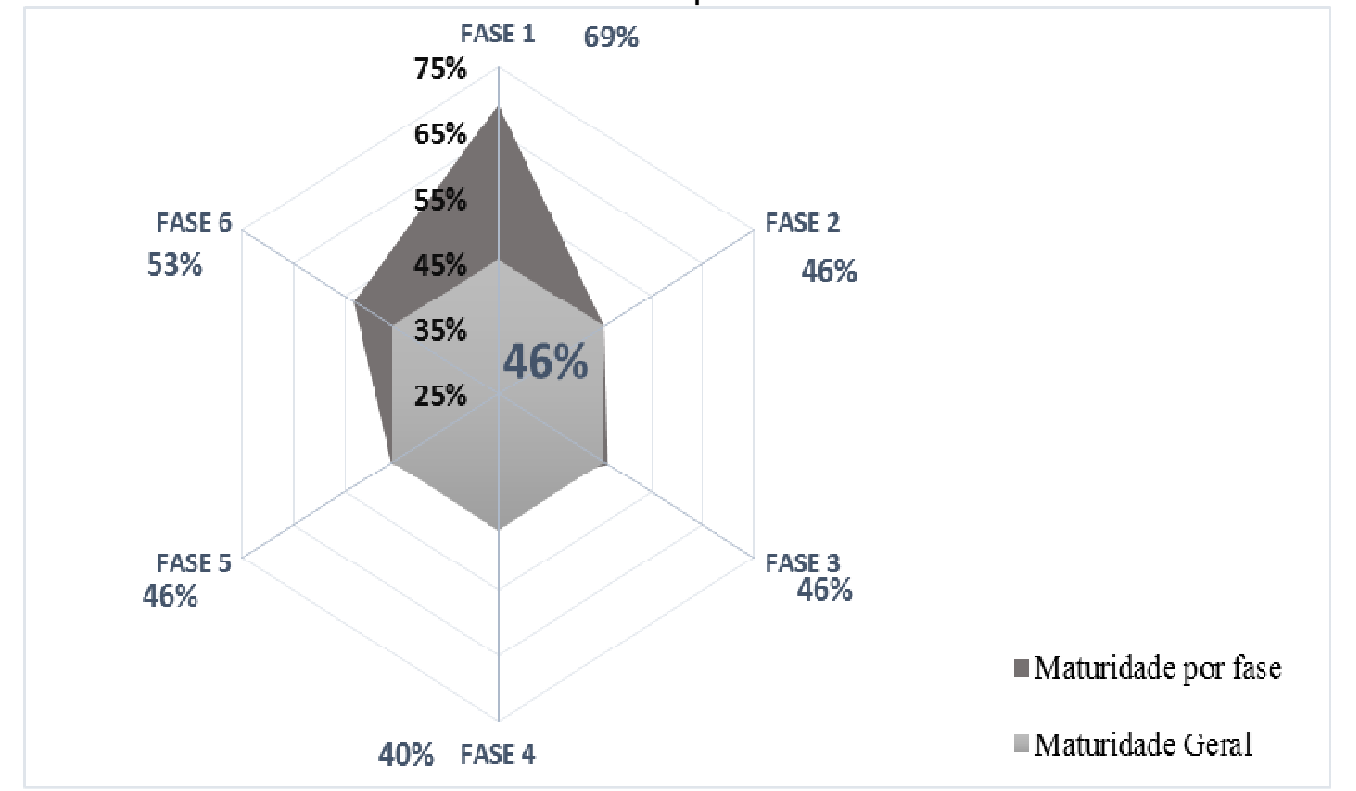

Fonte: Dados da pesquisa.

O Gráfico 7 apresenta o resultado por fase e o resultado geral. Observa-se que a Fase 1 atingiu a maior pontuação (69\%), sendo considerada a fase mais madura. A Fase 4 é considerada a fase menos madura e atingiu $40 \%$ na pontuação. A Fase 1 refere-se à infraestrutura de TIC como suporte à GC e a Fase 4 refere-se às estratégias de construção do conhecimento. $O$ resultado pode indicar que a Empresa "A" privilegia, atualmente, a TIC em detrimento a outros aspectos da GC.

Como indicado pela ferramenta, na Fase 3, os gestores foram unânimes ao indicarem que a Empresa " $A$ " não possui uma estratégia de GC formalmente implantada. A afirmação do Gestor E1corrobora esse resultado: "[...] sem dúvida, hoje fazemos muito mais gestão da informação do que gestão do conhecimento. Podem existir iniciativas isoladas de alguns setores e equipes, mas a cultura da gestão do conhecimento não faz parte da nossa realidade atualmente".

De acordo com a metodologia de avaliação do modelo S-KMMM, a Empresa "A" está no nível de maturidade "Inicial" e só passará para o próximo nível ao atingir $100 \%$ da Fase 1 . Além disso, de acordo com Kruger e Snyman (2007a), a evolução da maturidade é sequencial, ou 
Carlos Henrique Cotta Natale; Jorge Tadeu Ramos Neves; Rodrigo Baroni de Carvalho

Maturidade em gestão do conhecimento: análise das percepções dos gestores de uma grande empresa de construção civil

seja, é necessário atingir $100 \%$, fase a fase, para que a empresa possa considerar-se totalmente madura em seus processos e práticas de GC. Levando essa informação em consideração, em conjunto com o resultado do modelo aplicado, a Empresa "A" poderia iniciar um projeto de GC com a melhoria em sua infraestrutura de TIC, para melhor suporte às práticas de GC. Além disso, a divulgação do projeto pode ser importante, para a criação de uma cultura, informando prazos, práticas que serão implantadas, setores que serão envolvidos e as fases que serão atendidas naquele momento.

\section{CONCLUSÕES}

Nesta pesquisa o caso de uma grande empresa do segmento de construção civil pesada foi analisado com o intuito de responder qual a percepção dos gestores em relação à maturidade das práticas de gestão do conhecimento na organização. Para isso foi realizada uma revisão da literatura sobre gestão do conhecimento e modelos de maturidade em gestão do conhecimento. Alguns autores consideram que a aplicação de um modelo de maturidade em gestão do conhecimento pode ser útil para identificar processos e práticas de GC utilizadas em uma organização (KHATIBIAN; HASAN; JAFARI, 2010; KRUGER; SNYMAN, 2007a; KURIAKOSE et al., 2010; PEE; KANKANHALLI, 2009; OLIVEIRA et al., 2011; ROBINSON et al., 2006).

Uma vez definido o modelo de maturidade em GC para ser aplicado empiricamente, os 15 principais gestores da empresa objeto deste estudo de caso, foram entrevistados e convidados a responder ao questionário utilizado como ferramenta de avaliação da maturidade em gestão do conhecimento. $\mathrm{O}$ resultado do modelo aplicado (Gráfico 7) mostrou que a Empresa " $A$ " possui uma maturidade em estágio inicial e a pontuação, considerando a percepção dos 15 gestores, foi de $46 \%$, ou 163,6 pontos, de um total possível de 358 . 
Carlos Henrique Cotta Natale; Jorge Tadeu Ramos Neves; Rodrigo Baroni de Carvalho

Maturidade em gestão do conhecimento: análise das percepções dos gestores de uma grande empresa de construção civil

Uma análise qualitativa das entrevistas e do resultado do questionário também foi realizada. Percebe-se que, na Empresa "A", processos e práticas de GC são realizados de maneira isolada, intuitiva e informal, o que corrobora com o resultado encontrado a partir da aplicação do modelo S-KMMM.

Finalmente, é possível afirmar que, a partir da revisão da literatura, da análise das entrevistas e do resultado da aplicação do modelo de maturidade em GC, criado por Kruger e Snyman (2007a) e Kruger e Johnson (2010), foi possível identificar como os gestores da Empresa "A" percebem a evolução das práticas de gestão do conhecimento na organização. A resposta à afirmação V100 do KMMMQ demonstra, de uma forma resumida, a percepção da evolução da maturidade em GC, na empresa, ao longo dos últimos 5 anos (GRÁFICO 6). De maneira geral, os gestores pareceram interessados nos benefícios que a GC podem trazer para seus setores e para a empresa. Isso é percebido pelos gestores mesmo que muitos processos e práticas de GC não estejam sendo adotados na empresa.

Embora o resultado da aplicação do modelo S-KMMM na Empresa "A" tenha se mostrado eficaz nos seus objetivos, algumas limitações puderam ser observadas. Um modelo científico baseado em percepções não leva em consideração métricas objetivas. A ideia de se medir a maturidade em GC utilizando-se como ferramenta um questionário baseado apenas na percepção, seja de gestores, seja de outros funcionários, pode criar distorções da realidade, uma vez que é possível confrontar o resultado com nenhum dado ou estatística. Essas distorções da realidade podem ocorrer por desconhecimento do respondente sobre o tema, por falta de clareza nas perguntas, ou pelo fato do respondente ter uma visão otimista ou pessimista demais. Além disso, o modelo considera a média aritmética simples dos resultados alcançados por todos os respondentes como sendo a medida para a 
Carlos Henrique Cotta Natale; Jorge Tadeu Ramos Neves; Rodrigo Baroni de Carvalho

Maturidade em gestão do conhecimento: análise das percepções dos gestores de uma grande empresa de construção civil

maturidade, o que nem sempre pode refletir a realidade, sendo muitas vezes mais indicado o uso da mediana.

Ainda sobre a ferramenta de avaliação, percebeu-se que o questionário, de uma maneira geral, é composto por perguntas pertinentes, mas, ainda assim, falta espaço para flexibilidade e evolução do modelo, ou seja, o modelo poderia permitir um espaço para que perguntas e observações mais pertinentes à visão e à cultura da empresa fossem incluídas na avaliação. Esses pontos foram observados em todos os modelos comparados nesta pesquisa.

De qualquer forma, observou-se que a aplicação do modelo de maturidade em GC na Empresa "A" foi útil para que os gestores conhecessem melhor os processos de GC e seus benefícios. A partir da aplicação do modelo, os gestores começaram a perceber e a discutir relações positivas de uma possível implantação formal da GC na empresa.

As conclusões desse trabalho reforçam a abordagem de Weber et al. (2002) que defendem que a existência de padrões para GC permitirá que trabalhos futuros comecem em um patamar mais alto, evitando a reinvenção da roda que a própria GC tanto critica. Para os autores, os argumentos contra a padronização da GC podem ser classificados como preocupações gerais associadas a qualquer tipo de padronização. As pesquisas realizadas por Weber et al. (2002) no âmbito do Fórum Europeu de GC resultaram na identificação das seguintes prioridades para as empresas participantes: existência de uma estrutura para GC, definição de uma terminologia comum e de abordagens padronizadas para implementação. De acordo com Ehms e Langen (2002), o primeiro passo rumo a uma GC menos amadora e mais profissional consiste na avaliação sistemática das iniciativas organizacionais de GC, permitindo a identificação de problemas e a realização de ajustes. 
Carlos Henrique Cotta Natale; Jorge Tadeu Ramos Neves; Rodrigo Baroni de Carvalho

Maturidade em gestão do conhecimento: análise das percepções dos gestores de uma grande empresa de construção civil

Considerando-se os resultados alcançados e as limitações percebidas, alguns estudos futuros sobre o tema podem ser realizados, como por exemplo, aplicar o mesmo modelo na mesma empresa, porém com a ampliação do universo de pesquisa, seja com a participação de mais gestores, seja com a participação de funcionários de nível operacional (assistentes, técnicos, analistas e engenheiros) ou, aplicar o modelo S-KMMM a outra empresa do mesmo segmento, porte e faturamento, e comparar os resultados. Adicionalmente, o mesmo questionário pode ser aplicado de maneira longitudinal a cada ano de forma a acompanhar a evolução da empresa. Tal prática está na essência de todos os modelos de maturidade que percebem que a avaliação deve ser um processo contínuo de forma a permitir a identificação dos pontos fortes bem como das oportunidades de melhoria, contribuindo assim para fazer da busca da maturidade uma grande jornada de aprendizagem organizacional.

\section{REFERÊNCIAS}

ARAZY, O.; GELLATLY, I. R. Corporate Wikis: The Effects of Owners' Motivation and Behavior on Group Members' Engagement. Journal of Management Information Systems, Armonk, v. 29, n. 3, p. 87-116, jan. 2012.

AUGUSTO, Rafael. Knowledge management maturity model the case study of a portuguese technology. 2012. $44 \mathrm{f}$. Dissertação (Mestrado em Ciência Corporativa) - ISEG - School of Economics and Management, Lisboa, 2012.

BASKERVILLE, Richard; DULIPOVICI, Alina. The theoretical foundations of knowledge management. Knowledge Management Research \& Practice, Basingstoke, v. 4, n. 2, p. 83-105, 2006.

CAMPOS, Claudinei José Gomes. Método de análise de conteúdo: ferramenta para a análise de dados qualitativos no campo da saúde. Revista Brasileira de Enfermagem, Brasília, v. 57, n. 5, p. 611-614, 2004. 
Carlos Henrique Cotta Natale; Jorge Tadeu Ramos Neves; Rodrigo Baroni de Carvalho

Maturidade em gestão do conhecimento: análise das percepções dos gestores de uma grande empresa de construção civil

CHOI, Sue Young; LEE, Heeseok; YOO, Youngjin. The impact of information technology and transactive memory systems on knowledge sharing, application, and team performance: a field study. MIS

Quarterly, Minneapolis, v. 34, n. 4, p. 855-870, 2010.

COSTA, Cleyverson P.; MOURA, Hermano P. de; LUNA, Alexandre J. $\mathrm{H}$. de $\mathrm{O}$. Modelos de maturidade de gestão do conhecimento: uma análise comparativa. Knowledge Creation Diffusion Utilization, p.1-8, 2009.

CUESTA, Juan Carlos Zulueta. Los elementos de gestión del conocimiento en la transferencia de tecnologías de la universidad a la empresa. Contribuciones a las ciencias sociales, [S. I.], p. 1-12, maio 2011.

DALKIR, Kimiz. Knowledge management in theory and practice. Boston: Elsevier, 2005.

DAVENPORT, Thomas H. Ecologia da informação: porque só a tecnologia não basta para o sucesso na era da informação. São Paulo: Futura, 1998.

EHMS, Karsten; LANGEN, Manfred. Holistic development of knowledge management with knowledge management maturity model. 2002.

Disponível em: <http://www.kmmm.org>. Acesso em: 8 dez. 2014.

FONTANILLAS, Carlos Navarro; CRUZ, Eduardo Picanço;

GONÇALVES, Jaqueline Pimentel de Souza. A gestão do conhecimento e os processos de informações nas organizações: estudo de caso em uma empresa off shore. Sustainable Business International Journal, [S. I.], n. 18, p. 1-28, 2012.

GONÇALO, Cláudio Reis; JUNGES, Fabio Miguel; BORGES, Maria de Lourdes. Avaliação da gestão do conhecimento: modelos de mensuração. In: ENCONTRO NACIONAL DE ENGENHARIA DE PRODUÇÃO, 30., 2010, São Carlos. Anais... São Carlos: ABEPRO, 2010. p.15.

JUMO, Innocent. Knowledge Management Maturity Assessment in the Roads Engineering Environment. In: CONFERENCE ON ASPHALT PAVEMENTS FOR SOUTHERN AFRICA. 10., 2011, KwaZulu-Natal. Anais... Pretoria: [s. n.], 2011.

KHATIBIAN, Neda; HASAN, Tahmoores; JAFARI, Hasan Abedi. Measurement of knowledge management maturity level within organizations. Business Strategy Series, United Kingdom, v. 11, n.1, p. 54-70, 2010. 
Carlos Henrique Cotta Natale; Jorge Tadeu Ramos Neves; Rodrigo Baroni de Carvalho

Maturidade em gestão do conhecimento: análise das percepções dos gestores de uma grande empresa de construção civil

KRUGER, Cornelius Johannes; SNYMAN, Maria Magdalena

Margaretha. Formulation of a strategic knowledge management maturity model. SA Journal of Information Management, Johannesburg, v. 7, n. 2, p. 1142-1153, 2007a.

KRUGER, Cornelius Johannes; SNYMAN, Maria Magdalena Margaretha. Guidelines for assessing the knowledge management maturity of organizations. SA Journal of Information Management, Johannesburg, v. 9, n. 3, p. 1-12, 2007b.

KRUGER, Cornelius Johannes; JOHNSON, R. D. Assessment of knowledge management growth: a South Africa perspective. Aslib Proceedings, London, v. 61, n. 6, p. 542-564, 2009.

KRUGER, Cornelius Johannes; JOHNSON, R. D. Knowledge management maturity according to organizational size: a south african perspective. In: EUROPEAN CONFERENCE ON INFORMATION SYSTEMS,18., 2010, Pretoria. Anais... Pretoria, 2010.

KURIAKOSE, K.K. et al. Knowledge management maturity models: a morphological analysis. Journal of Knowledge Management Practice, Kalpakkam, v. 11, n. 3, p. 1-10, 2010.

MANLY, Bryan F. Métodos estatísticos multivariados: uma introdução. 3. ed. Porto Alegre: Bookman, 2008.

NEVES, José Luis. Pesquisa qualitativa: características, usos e possibilidades. Caderno de Pesquisas em Administração, São Paulo, v. 1, n. 3, p. 1-5, 1996.

OLIVEIRA, Mírian et al. Proposta de um modelo de maturidade para Gestão do Conhecimento: $\mathrm{KM}^{3}$. Revista Portuguesa e Brasileira de Gestão, Rio de Janeiro, p. 11-24, 2011.

PEE, L. G.; KANKANHALLI, Atreyi. A model of organizational knowledge management maturity based on people, process, and technology. Journal of Information \& Knowledge Management, United Kingdom, v. 8, n. 2, p. 79-99, 2009.

PÉREZ, Arias; ENRIQUE, José. Asociaciones entre madurez de gestión del conocimiento y desempeño innovador : organización y personas, e interpretación. Corporación Universitaria Lasallista, Colombia, v. 9, n. 1, p. 86-95, 2012.

RAMANIGOPAL, C. Knowledge management strategies for successful implementation in aerospace industry. Advances In Management, v. 5, n. 17, p. 17-22, 2012. 
Carlos Henrique Cotta Natale; Jorge Tadeu Ramos Neves; Rodrigo Baroni de Carvalho

Maturidade em gestão do conhecimento: análise das percepções dos gestores de uma grande empresa de construção civil

ROBINSON, Herbert S. et al. Knowledge management practices in large construction organizations. Business Process Management Journal, Bradford, v. 12, n. 6, p. 793-808, 2006.

SINHA, R. A Comparative Analysis of Knowledge Management Process Maturity Models. International Journal of Innovative Research and Studies, USA, v. 2, n. 5, p. 221-234, 2013.

SMITH, K. E. N. G.; MITCHELL, T. R.; SUMMER, C. E. Top level management priorities in different stages of the organizational life cycle. Academy of Management Journal, Champaign, v. 28, n. 4, p. 799-820, 1985

TARAPANOFF, Kira. Informação, conhecimento e inteligência em corporações: relações e complementaridade. Brasília: IBICT, 2006.

VAN-DE-VEM, A. H. Explaining development and change. Academy of Management Review, Mississippi, v. 20, n. 3, p. 510-540, 1995.

VERGARA, Sylvia Constant. Começando a definir a metodologia. In: Projetos e relatórios de pesquisa em administração. 7. ed. São Paulo: Atlas, 2006. p. 1-7.

XAVIER, M. B. G. Mensuração da maturidade da governança de ti na administração direta federal brasileira. 2010. Dissertação (Mestrado em Ciência da Informação) - Universidade Católica de Brasília, Brasília, 2010.

WEBER, Frithjof et al. Standardization in knowledge management: towards a common $\mathrm{km}$ framework in Europe. In: UNICOM SEMINAR, 2002, Londres. Proceedings... Londres: 2002.

\section{Title}

Knowledge management maturity: analysis of manager's perceptions of a large construction company

\section{Abstract}

Introduction: From the application of a Knowledge Management (KM) maturity model, an organization may be able to identify KM practices that can be improved and, or deployed.

Objective: The purpose is to identify the perception of top managers regarding the maturity of Knowledge Management practices within a large construction company.

Methodology: This qualitative and descriptive research was conducted with the top management group (15 executives) in two phases: preliminary interview 
Carlos Henrique Cotta Natale; Jorge Tadeu Ramos Neves; Rodrigo Baroni de

Carvalho

Maturidade em gestão do conhecimento: análise das percepções dos gestores de uma grande empresa de construção civil

and a semi structured questionnaire (100 questions and 6 levels) based upon Strategic Knowledge Management Maturity Model (KRUGER; SNYMAN, 2007b).

Results: The organization was classified in the initial stage of knowledge management. The S-KMMM allowed the identification of isolated departmental initiatives and $\mathrm{KM}$ processes that can deployed or enhanced.

Conclusions: It was observed that the application of KM maturity model has been useful for the managers to recognize that the current KM practices are isolated, intuitive and informal. The application of S-KMMM has proven to be valid to the systematic evaluation and the strategic alignment of KM corporate initiatives.

Keywords: Knowledge management maturity model. Knowledge management. Knowledge measurement. Construction industry.

\section{Titulo}

Madurez de la gestión del conocimiento: análisis de las percepciones de los gestores de una gran empresa de construcción civil

\section{Resumen}

Introducción: A partir de la aplicación de un modelo de madurez para la gestión del conocimiento, una empresa puede ser capaz de identificar las prácticas de gestión del conocimientos que se pueden mejorar y, o implantar.

Objetivo: El propósito es identificar las percepciones de los gerentes en relación a la madurez de las prácticas de gestión del conocimiento en una grande empresa de construcción.

Metodología: La investigación cualitativa descriptiva ocurrió en dos pasos: 15 gestores fueron entrevistados en un primer paso y, en un segundo paso, esos gestores respondieron un cuestionario embazado en Strategic Knowledge Management Maturity Model (KRUGER; SNYMAN, 2007b).

Resultados: Observó que la empresa está en las primeras etapas de la gestión del conocimiento. Fue posible identificar iniciativas aisladas $Y$ informales de gestión del conocimiento y, también, procesos y prácticas de gestión de conocimiento que se pueden implementar y, o, mejorar en la organización.

Conclusiones: Se observó que la aplicación del modelo de madurez en gestión del conocimiento ha sido útil para que los administradores de la empresa estudiada conocieran mejor los procesos de gestión del conocimiento y sus beneficios. La aplicación de S-KMMM se mostró valida para evaluación sistémica y alineamiento estratégico das iniciativas corporativas de gestión de conocimiento.

Palabras clave: Modelos de madurez en gestión del conocimiento. Gestión del conocimiento. Medición del conocimiento. Industria de construcción.

Recebido: 28.12 .2014

Aceito: 03.12.2015

Inf. Inf., Londrina, v. 21, n. 1, p. 375 - 406, jan./abr. 2016 